\title{
Phytochemical analysis and free radical scavenging activity of Isoberlinia doka leaves
}

\author{
Ahmed H. A. *, Halilu M. E., Mathias S. N. and Lawal M. \\ Department of Pharmacognosy and Ethnomedicine, Faculty of Pharmaceutical Sciences, Usmanu Danfodiyo University, \\ Sokoto- Nigeria
}

Publication history: Received on 14 June 2018; revised on 05 July 2018; accepted on 09 July 2018

Article DOI: https://doi.org/10.30574/gscbps.2018.4.1.0049

\begin{abstract}
Isoberlinia doka is dominant species in the savannah of West Africa belonging to the family Fabaceae. It is used in traditional medicine for treatment of muscular - skeletal system disorders, Jaundice scorpion bites, Convulsion, diabetes, ulcer, wounds and cough. The objectives of the study are to determine the pharmacognostic and antioxidant activity of Isoberlinia doka leaves. Three extracts of Isoberlinia doka leaves were obtained by sequential maceration using n-hexane, ethyl acetate and methanol The extracts were screened qualitatively for the presence of saponins, carbohydrates, tannins, flavonoids, cardiac glycosides, anthraquinones and alkaloids using standard procedures. Thin layer chromatography was carried out to determine the separation profile of various extracts. Antioxidant activity of the methanol leaves extract of Isoberlinia doka was determined using 1, 1-diphenyl-2-picrylhydrazyl radical (DPPH) Assay. The phytochemical screening of the methanol extract revealed the presence of alkaloids, flavonoids, tannins, cardiac glycosides and saponins. The methanol leaves extract of Isoberlinia doka demonstrated strong radical scavenging activity and reducing power ability with concentration dependent responses. The results of this study suggest that the plant can serve as a good source of antioxidant which can aid in the management of diseases associated with oxidative stress.
\end{abstract}

Keywords: Isoberlinia doka; Free radical scavenging; Phytochemical analysis; 1, 1-diphenyl-2-picrylhydrazyl radical (DPPH) assay

\section{Introduction}

Medicinal plants play a pivotal role in the health care since ancient times. Many cultures use mainly plant based drugs or formulations to treat various human ailments because they contain chemical constituents with therapeutic value [1] Free radicals play a major part in the development of chronic and degenerative ailments, the imbalance in the ROS generating and scavenging systems in the body causes damage of tissue and cellular organs [2]. Reactive Oxygen Species (ROS) such as superoxide anion, hydroxyl radical and hydrogen peroxide play a crucial role in the development of various ailments such as arthritis, asthma, dementia, mongolism, carcinoma and Parkinson's disease. The free radicals in the human body are generated through aerobic respiration or from exogenous sources [3]. Antioxidants from plant materials terminate the action of free radicals thereby protecting the body from various diseases [4]. Medicinal plants are important source of antioxidant compounds; these natural antioxidants reduce the risk of many chronic diseases. The secondary metabolites- like phenolic compounds and flavonoids- from plants have been reported to be the potent free radical scavengers, they are found in all parts of plants such as leaves, fruits, seeds, roots and barks [5].

\footnotetext{
${ }^{*}$ Corresponding author

E-mail address: aliyuhameedahmed@gmail.com
}

Copyright (C) 2018 Author(s) retain the copyright of this article. This article is published under the terms of the Creative Commons Attribution Liscense 4.0. 
Isoberlinia doka (Fabaceae) is a tree 10-18m high or more. Isoberlinia doka is distributed in west and central Africa from Guinea in the west to Sudan, Uganda in the east. It is not known to occur in the South of the Equator [6]. The tree has been used by traditional medical practitioners for the treatment of diabetes, ulcer, wounds and cough [7]. The study was carried out to determine the phytochemicals present the free radical scavenging activity of the plant.

\section{Material and methods}

\subsection{Plant collection and identification}

The Plant was collected in Samaru, Zaria Local Government Area of Kaduna State, Nigeria in April, 2017. The plant was identified and authenticated at the Herbarium of the Department of Biological Sciences, Ahmadu Bello University Zaria, Nigeria, where the voucher specimen is deposited.

\subsection{Drying and storage}

The leaves of Isoberlinia doka was shade dried for seven days, after which it was grounded using a pestle and mortar, weighed and packed in an airtight container for further use.

\subsection{Method of extraction}

The powdered leaves of Isoberlinia doka was extracted by maceration, using methanol as solvent. $500 \mathrm{~g}$ of the powdered sample was weighed and macerated in $2500 \mathrm{ml}$ of methanol for 24 hours. The extract was filtered.

\subsection{Phytochemical analysis}

N-hexane, ethyl acetate and methanol extracts were analyzed for presence of phytochemicals using standard procedures [8].

\subsubsection{Test for Flavonoids}

Shinoda test

$10 \mathrm{mg}$ of extract was added to pinch of magnesium turnings and 1-2 drops of concentrated hydrochloric acid was added. Formation of pink color indicates the presence of Flavonoids.

Lead acetate test

$10 \mathrm{mg}$ of extract was taken and few drops of $10 \%$ lead acetate solution was added. Appearance of yellow colour precipitate indicates the presence of flavonoids.

\subsubsection{Test for phenols and tannins}

Lead acetate test

$10 \mathrm{mg}$ of extract was taken and $0.5 \mathrm{ml}$ of $1 \%$ lead acetate solution was added and the formation of precipitate indicates the presence of tannins and phenolic compounds.

Ferric chloride test

$5 \mathrm{mg}$ of extract was taken and $0.5 \mathrm{ml}$ of $5 \%$ ferric chloride was added. The development of dark bluish black color indicates the presence of tannins.

Sodium hydroxide test

$5 \mathrm{mg}$ of extract was dissolved in $0.5 \mathrm{ml}$ of $20 \%$ sulphuric acid solution. Followed by addition of few drops of aqueous sodium hydroxide solution, it turns blue which indicates the presence of phenols. 


\subsubsection{Test for anthraquinones}

\section{Borntragers test}

About $0.5 \mathrm{~g}$ of the extract was taken into a dry test tube and $5 \mathrm{ml}$ of chloroform was added and shaken for 5 minutes. The extract was filtered and the filtrate was shaken with equal volume of $10 \%$ ammonia solution. A pink violet or red colour in the lower layer indicates the presence of anthraquinone.

\subsubsection{Test for carbohydrates}

\section{Molisch's test}

Small portion of the extract was put in a test tube; $10 \mathrm{ml}$ of distilled water was added and shaken vigorously and gently. The mixture was then filters and divided into two portions. To the first portion, two drops of Molish's reagent was added followed by few drops of concentrated sulphuric acid by the wall of the test tube. Formation of brown or purple ring at the interphase indicated the presence of carbohydrates.

Fehling's test

To the second portion of the filtrate, few drops of Fehling's solution A \& B was added and boiled for 5 minute on a water bath. Brick red coloration indicates the presence of reducing sugar.

\subsubsection{Test for alkaloids}

A small portion of the extract was stirred in $5 \mathrm{ml}$ of $1 \%$ aqueous hydrochloric acid on a steam bath, allowed to cooled and filtered. $1 \mathrm{ml}$ of the filtrate was treated with a few drops of Meyer's reagent and to another $1 \mathrm{ml}$ of the filtrate, a few drops of Dragendorff reagent was added. To another $1 \mathrm{ml}$ of the filtrate, a few drop of Wagner's reagent was added. Turbidity or precipitation with either of the reagents was taken as preliminary evidence for the presence of alkaloids in the extract being evaluated [9].

\subsubsection{Test for saponins}

Frothing test was used to detect the presence of saponins. Small quantity of the plant extract was mixed and shaken with water in a test tube. Frothing which persist on warming was taken as preliminary evidence for the presence of saponins [10].

\subsection{Radical scavenging activity DPPH assay}

The effect of Isoberlinia doka on DPPH radical was assayed using the modified method of Mensor et al [11] Sample stock solution of each extract $(0.1 \mathrm{mg} / \mathrm{ml})$ will be diluted with methanol into various concentrations: 100, 80, 60, 40, $20 \mu \mathrm{g}$ respectively. To each sample, $2.5 \mathrm{ml}(20,40,60,80$, and $100 \mu \mathrm{g} / \mathrm{ml}$ in methanol) will be added to $1 \mathrm{ml}$ of DPPH solution $(0.2 \mathrm{mM}$ in methanol). After 30 minutes of reaction at room temperature, the absorbance of the solution will then be measured at $518 \mathrm{~nm}$. The free radical scavenging activity of the extract will be determined by comparing its absorbance with that of a blank solution (no sample). The ability to scavenge the DPPH radical will be calculated using the following equation;

$$
\text { Percentage inhibition of absorbance }=\frac{A^{\prime} \text { control }-A^{\prime} \text { sample }}{A \text { control }} \times 100
$$

Where A'control is the absorbance value of the control group, and A'sample is the absorbance of the sample.

\section{Results and discussion}

The phytochemical screening of the Isoberlinia doka leaves revealed the presence of alkaloids, flavonoids, tannins and saponins in the methanol extract. The methanol leaves extract of Isoberlinia doka demonstrated strong radical scavenging activity and reducing power ability with concentration dependent responses comparable to ascorbic acid.

The extracts revealed the presence of saponins, carbohydrates, tannins, flavonoids, cardiac glycosides and alkaloids. The medicinal values of plants are due to the presence of phytochemicals, which produce definite physiological actions [12]. Phenolic compounds such as tannins, flavonoids and saponins show free radical activity [13]. Phenolic compounds from medicinal plants possess strong antioxidant activity and may help to protect the cells against the oxidative damage 
caused by free-radicals [14]. They are well known as radical scavengers, metal chelators, reducing agents, hydrogen donors, and singlet oxygen quenchers [15].

Table 1 Preliminary phytochemical screening of Isoberlinia doka leaves

\begin{tabular}{lllcll}
\hline $\begin{array}{l}\text { Sr. } \\
\text { No. }\end{array}$ & Plant constituents & Test & $\begin{array}{l}\text { N-hexane } \\
\text { extract }\end{array}$ & $\begin{array}{l}\text { Ethyl acetate } \\
\text { extract }\end{array}$ & $\begin{array}{l}\text { Methanol } \\
\text { extract }\end{array}$ \\
\hline 1 & Alkaloids & Wagner & Absent & Absent & Present \\
& & Dragendorff & Absent & Present & Present \\
& & Mayer & Absent & Present & Present \\
2 & Flavonoids & Shinoda & Absent & Present & Present \\
& & Lead sub-acetate & Absent & Present & Present \\
3 & Saponins & Frothing test & Absent & Present & Present \\
4 & Tannins \& Phenols & Lead acetate & Absent & Present & Present \\
& & Ferric chloride & Absent & Present & Present \\
5 & Anthraquinones & Borntrager's & Absent & Absent & Absent \\
6 & Carbohydrates & Molish & Present & Present & Present \\
& & Fehling & Present & Present & Present \\
7 & Steroids & Salkowski test & Present & Absent & Absent \\
\hline
\end{tabular}

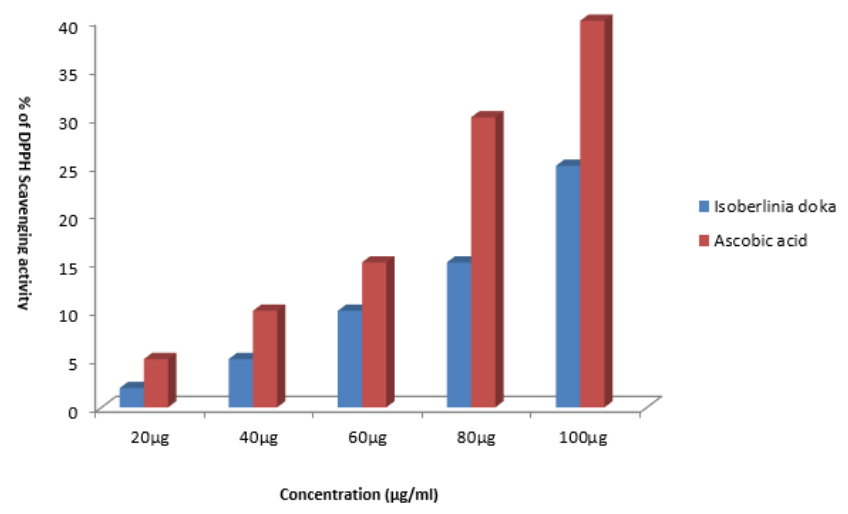

Figure 1 DPPH free radical scavenging activity of Isoberlinia doka

Antioxidants from plant materials terminate the action of free radicals thereby protecting the body from various diseases [4]. DPPH is a stable radical commonly used to determine the antioxidant activity of various compound. It is a stable free radical because of its spare electron delocalization over the whole molecule. This method is based on the reduction of DPPH in the presence of a hydrogen-donating antioxidant, inducing a color change from purple to yellow at $517 \mathrm{~nm}$. The degree of reduction in absorbance measurement indicates the radical scavenging (antioxidant) power of the extract [16]. The result of the antioxidant activity shows a dose dependent free radical scavenging activity comparable to ascorbic acid. Several studies have shown that the scavenging effect on the DPPH radical increases sharply with the increasing concentration of the samples and standards to a certain extent [17].

\section{Conclusion}

The results of this study suggest that the plant can serve as a good source of antioxidant which can aid in the management of diseases associated with oxidative stress.

\section{Compliance with ethical standards}

\section{Acknowledgments}

The authors are grateful to the Faculty of Pharmaceutical sciences, Usmanu Danfodiyo University Sokoto for their support during this research. 


\section{Disclosure of conflict of interest}

The authors declare that there is no conflict of Interest

\section{References}

[1] Nithya N and Balakrishnan KP. (2011). Evaluation of some medicinal plants with antioxidant activity. International Journal of Pharmtech Research, 3(1), 381-385.

[2] Schieber M and Chandel NS. (2014). ROS function in redox signaling and oxidative stress. Current biology, 24(10), 453-462.

[3] Halliwell B and Gutteridge JMC. (1990). Role of free-radicals and catalitic metal ions in human disease: an overview. Methods Enzymology, 186, 1- 85.

[4] Lai LS, Chou ST and Chao WW. (2001). Studies on the antioxidative activities of Hsiantsao (Mesona procumbens. Hems l.) leaf gum. Journal of Agricultural and Food Chemistry, 49, 963-968.

[5] Mohamed M, Wadah JAO, Shereen OA, Amna A, Mahgoub SE. (2017). In vitro antioxidant activity of a flavonoid compound isolated from methanolic extract of Helianthus annuus leaves (Asteraceae). Der Pharmacia Letter, 9 (6), 28-34.

[6] Kenneth AK. (1968). A survey of vegetation in Zaria. Vegetation, 15(4), 244-268.

[7] Abdulkadir IE, Aliyu AB, Ibrahim MA, Audu SBD and Oyewale AO. (2011). Antioxidant activity and mineral elements profiles of Isoberlinia doka leaves from Nigeria. Australian Journal of Basic and Applied Sciences, 5(12), 2507-2512.

[8] Kokate CK, Purohit AP and Gokhale SB. (1995). Pharmacognosy, 3rd edition, Nirali Prakashan, Pune.

[9] Harborne JB. (1973). Phytochemical methods, A guide to modern technique of plant analysis, Chapman and Hill, London, 279.

[10] Sofowora, A. (1984). Research on medicinal plants and traditional medicine in Africa. Journal of Alternative Complementary Medicine, 2, 365-372.

[11] Mensor LL, Meneze FS, Leitao GG, Reis AS, Dos santor JC, Coube CS and Leitao SG. (2001). Screening of brazilian plant extracts for antioxidant activity by the use of DPPH free radical method. Phytotherapy research, 15, 127130.

[12] Akinmoladun AC, Ibukun EO, Afor E, Akinrinlola BL, Onibon TR, Akinboboye AO, Obuotor EM and Farombi EO. (2007). Chemical constituents and antioxidant activity of Alstonia boonei. African Journal of Biotechnology, 6(10), 1197-1201.

[13] Shahidi F and Wanasundara PKJ. (1992). Phenolic antioxidants. Critical Review and Food Science Nutrition, 32, 67-103.

[14] Kahkonen MP, Hopia AI, Vuorela HJ, Rauha JP, Pihlaja K, Kujala TS and Heinonen M. (1999). Antioxidant activity of plant extracts containing phenolic compounds. Journal of Agricultural and Food Chemistry, 47, 3954-3962.

[15] Proestos C, Boziaris, I. S., Nychas, GJE and Komaitis M. (2006). Analysis of flavonoids and phenolic acids in Greek aromatic plants: investigation of their antioxidant capacity and antimicrobial activity. Food Chemistry, 95, 66467.

[16] Abdou MOA, Ambaliou S and Latifou L. (2015). Antioxidant activity and total phenolic, flavonoid and flavonol contents of the bark extracts of Acacia ataxacantha. Journal of Pharmacognosy and Phytochemistry, 4(2), 172178.

[17] Motalleb G, Hanachi P, Kua SH, Fauziah O and Asmah R. (2005). Evaluation of phenolic content and total antioxidant activity in Berberis vulgaris fruit extract. Journal of Biological Science, 5, 648-653.

\section{How to cite this article}

Ahmed HA, Halilu ME, Mathias SN and Lawal M. (2018). Phytochemical analysis and free radical scavenging activity of Isoberlinia doka leaves. GSC Biological and Pharmaceutical Sciences, 4(1), 48-52. 